\title{
CONCEPÇÕES DE LEITURA E FORMAÇÃO DO LEITOR NOS ANOS INICIAIS DO ENSINO FUNDAMENTAL NOS DOCUMENTOS OFICIAIS DE ENSINO
}

\author{
CONCEPCIONES DE LECTURA Y FORMACIÓN DE LECTORES EN LOS PRIMEROS \\ AÑOS DE EDUCACIÓN FUNDAMENTAL EN DOCUMENTOS OFICIALES DE \\ ENSE N ANZA
}

\section{READING CONCEPTIONS AND READER FORMATION IN THE FIRST YEARS OF FUNDAMENTAL EDUCATION IN OFFICIAL TEACHING DOCUMENTS}

\author{
Marconde Ávila BANDEIRA ${ }^{1}$ \\ Rosiane PORTILHO ${ }^{2}$
}

RESUMO: O processo de formação de um leitor é construído através de estímulos e mediação, esse processo vem sendo frequentemente abordado, por suas dificuldades em formar um leitor com autonomia, uma vez, que tem crescido o número de alunos que chegam ao fim do ensino fundamental com dificuldades ao realizar a leitura de um simples texto, ou seja, com déficit na compreensão leitora. Através de estudos bibliográficos em autores que vem discutindo essa problemática, buscarei elucidar o processo de formação do leitor, sobre as concepções e metodologias que colaboram na formação de um leitor proficiente, amparado nos documentos oficiais de ensino nos eixos de leitura, e através destes buscarei evidenciar como a leitura situase dentro desses documentos e quais contribuições eles trazem na formação do leitor autônomo nos anos iniciais do ensino fundamental.

PALAVRAS-CHAVE: Leitura. Formação do leitor. Ensino-aprendizagem. Documentos oficiais.

RESUMEN: El proceso de formación de un lector se construye a través de estímulos y mediación, este proceso se ha abordado a menudo, debido a sus dificultades para formar un lector con autonomía, ya que el número de estudiantes que llegan al final de la escuela primaria con dificultades para leer un texto simple ha aumentado, es decir, con un déficit en la comprensión lectora. A través de estudios bibliográficos en autores que han estado discutiendo este problema, buscaré esclarecer el proceso de formación de lectores, sobre las concepciones y metodologías que colaboran en la formación de un lector competente, apoyándose en los documentos oficiales de enseñanza en los ejes de lectura, y a través de ellos trataré de destacar cómo se encuentra la lectura dentro de estos documentos y qué contribuciones aportan en la formación del lector autónomo en los primeros años de la escuela primaria.

PALABRAS CLAVE: Lectura. Formación del lector. Enseñanza-aprendizaje. Documentos oficiales.

${ }^{1}$ Universidade Federal do Pará (UFPA), Belém - PA - Brasil. Mestrando do Programa de Pós-graduação em Currículo e Gestão da Escola Básica, Núcleo de Estudos Transdisciplinares em Educação Básica. ORCID: https://orcid.org/0000-0001-8414-0761.E-mail: bandeira.neto77@gmail.com

${ }^{2}$ Universidade Federal do Pará (UFPA), Altamira - PA - Brasil. Graduanda do Curso de Pedagogia. ORCID: http://orcid.org/0000-0001-9279-9937.E-mail: annhyportilhoaraujo1@gmail.com 
ABSTRACT: The process of formation of a reader is built through stimulation and mediation, this process has often been addressed, for its difficulties in forming a reader with autonomy, since the growing number of students who reach the end of elementary school with difficulties in reading a simple text, that is, with a deficit in reading comprehension. Through bibliographical studies on authors who have been discussing this problem, I will try to elucidate the process of formation of the reader, on the conceptions and methodologies that collaborate in the formation of a proficient reader, based on the official teaching documents in the areas of reading, and through these I will try to highlight how reading lies within these documents and what contributions they bring to the formation of the autonomous reader in the initial years of elementary school.

KEYWORDS: Reading. Reader formation. Teaching-learning. Official documents.

\section{Introdução}

Muito tem sido discutido sobre as abordagens da leitura e a intensidade de como é trabalhada essa prática em sala de aula nos anos iniciais do ensino fundamental. No decorrer dos primeiros anos de escolarização do ensino fundamental alguns alunos apresentam dificuldades na aquisição da leitura e, que por vezes, continuam com tais dificuldades nos anos seguintes. Muitas vezes o aluno é mal interpretado pelo professor e, consequentemente, acarreta em problemas futuros na vida escola e social do educando, uma vez que a leitura é fundamental para o desenvolvimento da aprendizagem e exercício da cidadania. Assim, é sugerido que a habilidade da leitura se constitua como uma prática social e cultural (MARCUSCHI, 2008). Espera-se, portanto, que a escola contribua -por meio de suas práticas pedagógicas- na formação do leitor proficiente crítico-reflexivo (ROJO, 2008).

Em relação à formação universitária a nível de graduação em Pedagogia, evidencia-se, a partir dos estágios supervisionados, que muitos profissionais da educação ainda não têm uma dada consciência da importância da prática da leitura no processo de ensino-aprendizagem do aluno, o quão significante pode ser essa prática para o sucesso escolar destes, uma vez, que por consequência de uma concepção de leitura ultrapassada e de uma abordagem de leitura não adequada, vem crescendo o número de alunos que são egressos da educação básica com déficit ao realizar e compreender a leitura de textos simples, alunos estes que, por vezes, conseguem fazer a decodificação dos símbolos linguísticos escritos. No entanto não compreendem o que leem. Isso pode ser que esteja relacionado com as teorias e metodologias aplicadas ao ensino nos primeiros anos do Ensino Fundamental, a hipótese é de que uma prática de ensino defasada, ultrapassada e sem uma abordagem interacionista, possa contribuir para que o aluno se torne não proficiente na leitura. 
Diante disso, pretendemos refletir, a partir dos documentos oficiais de ensino, sobre as concepções de leitura e formação do leitor nos anos iniciais do ensino fundamental.

\section{Sobre a leitura nos anos iniciais do ensino fundamental}

A criança estudante dos anos iniciais do ensino fundamental - que corresponde a etapa do $1^{\circ}$ ao $5^{\circ}$ ano, está em fase de aquisição dos sentidos, explorações e descobertas do mundo e nada mais importante do que a leitura para dar suporte a conhecimentos sociais.

A reflexão sobre o estímulo da leitura nas series iniciais do EF é de extrema importância, como diz Coelho (2015):

O horizonte e perspectivas existem em conjunto e de certa forma não sofrem segregação. O hábito de leitura estimula a capacidade criadora, multiplica o vocabulário, simplifica a compreensão do que se lê, facilita a escrita, melhora a comunicação, amplia o conhecimento, acrescenta o senso crítico e ajuda na vida profissional. O contato com a leitura deve começar desde a tenra idade quando as crianças estão mais flexíveis com a curiosidade aguçada.

A criança nessa idade está em processo de construção e aquisição da compreensão do meio social no qual ela está inserida. Sendo assim, é necessário rever as práticas de ensino da leitura que são aplicadas nas series iniciais do ensino fundamental, assim, propor soluções para as dificuldades encontradas pelo educando, construindo com eles estratégias necessárias para a compreensão de textos, como forma de amenizar o número de alunos que saem do ensino básico com déficit na competência leitora.

A ausência de abordagens interativas de leitura em sala de aula, o não incentivo ao ato de ler em consonância com as dificuldades encontradas por professores, que por vezes se detém ao ensino, podem implicar na criança atraso na sua competência leitora e no desenvolvimento de seu processo de ensino aprendizagem gerando consequências futuras como: a falta de interatividade, criatividade, imaginação, senso crítico, autonomia e insucesso escolar. Diante disso, é importante que o professor/educador, busque conhecer e, nesse sentido, praticar o ensino e estímulo da leitura, desconstruindo os paradigmas de dificuldades da compreensão leitora que os alunos encontram em sua jornada acadêmica, contribuindo para que estes se tornem leitores proficientes.

Por conseguinte, desenvolver na criança o comportamento leitor nos anos iniciais do EF é algo importante e necessário a fazer, a leitura é um dos meios de comunicação mais importante na sociedade e é através dela que recebemos informações sobre tudo o que ocorre no mundo, por este motivo apresentar a cultura letrada e sua significância a criança é de suma importância, 
pois ela levará esse conhecimento por toda sua vida, fazendo uso da leitura de maneira correta, ou seja, lendo com proficiência.

Sendo assim, para que se faça uma leitura com proficiência é necessário que se compreenda o que se lê. Segundo Kleiman (2008), a leitura precisa permitir que o leitor apreenda o sentido do texto, não podendo transformar-se em mera decifração de signos linguísticos sem a compreensão semântica dos mesmos.

O ensino fundamental é um estágio educacional no qual devem ser efetivadas abordagens de leitura, com práticas de ensino que desenvolvam no educando estratégias de leitura, pois nesse espaço ocorrerá a interação com outras crianças, com outras culturas, troca de experiências. É o espaço onde será possibilitado à criança desenvolver aspectos cognitivos, permitindo a construção da identidade como sujeito social, é também onde será desenvolvido o processo de formação social, psicológica, de caráter intelectual e emocional da criança (MOURA; MARTINS, 2012, p. 87).

Portanto, acompanhar a criança no processo de aquisição da leitura, incentivá-las à busca pela autonomia, conduzi-las para que estas se tornem leitores críticos e reflexivos, requer do professor um olhar aprofundado sobre as metodologias de ensino e práticas a serem utilizadas, buscando desenvolver estratégias necessárias para o ensino da leitura, considerando as especificidades e o conhecimento prévio dos alunos em questão.

\section{Concepções de leitura e formação do leitor}

Nas escolas brasileiras o ensino da leitura está vinculado ao desenvolvimento da língua portuguesa, que é uma área da ciência linguística, que estuda a linguagem humana, estando articulada com a fala e a escrita e que tem como objeto de estudo grafemas, fonemas, palavras, frases e textos. As concepções de linguagem, leitura e suas práticas pedagógicas estão relacionadas com o meio social, político, econômico, cultural e com a interpretação e compreensão que se tem da realidade. Sob essa perspectiva, a concepção que o professor terá sobre a teoria da língua portuguesa determinará sua metodologia de ensino e prática em sala de aula.

Conforme Hoppe e Costa-Hubes (s/d) há concepções que a prática da leitura em sala de aula pauta-se no autor, embasando-se em uma gramática tradicional que prioriza a oralidade e a escrita, transformando-se em um ato de monólogo e particular de cada indivíduo. Outra concepção enfoca a leitura na perspectiva do texto, este segue as regras dos signos linguísticos, considerando a língua apenas como código, e a leitura do texto como decodificação. Há ainda 
a concepção sob a perspectiva do leitor, esta está pautada na atribuição e sentido que o leitor dará ao texto.

Nesse sentido Menegassi e Ângelo (2005, p. 18, apud HOPPE; COSTA-HUBES, s/d) afirmam que:

Os pressupostos teóricos que amparam cada uma dessas diferentes perspectivas de leitura envolvem uma visão diferente do que consiste o ato de ler e orientam e/ou justificam determinadas propostas didáticas em torno da compreensão da leitura, e da formação e do desenvolvimento do leitor na escola brasileira.

Dessa forma, a concepção de leitura que o educador terá, será determinante na sua prática em sala de aula, pode ser uma concepção em que a leitura é vista como algo importante e necessário, se construindo meios para ser abordada com significância, ou pode ser abordada em uma perspectiva de reprodução de texto, sem valor semântico atribuído.

Contudo há concepções de leitura que suscitam ao aluno interação e conhecimentos através dos textos, levando em conta fatores linguísticos e discursivos, desenvolvendo a capacidade de compreensão leitora e a autonomia na construção de significados linguísticos. Desenvolvendo no aluno habilidades na competência leitora e possibilidades na formação de leitores proficientes, pois, como supõe Bortoni-Ricardo (2012, p. 90), uma concepção que consista:

[...] em ajudar o aluno a estabelecer as relações entre o texto e o próprio conhecimento de mundo; a reconhecer os elementos linguísticos; a perceber a progressão temática, por meio de elementos sequenciadores; a desenvolver a metacognição, ou seja, o controle sobre as informações já obtidas com a leitura do texto, sinalizando, quando necessário, pontos de inferências.

Uma proposta de leitura que envolva o aluno como sujeito ativo no processo de ensino aprendizagem, que apresente todas as informações contidas no texto, que aborde a leitura como prática social Kleiman (2014). No entanto, a leitura vem sendo tradicionalmente implantada nas escolas como um ato mecânico de decodificação dos códigos e signos linguísticos, deixando de lado a real importância que ela tem no processo de ensino-aprendizado do aluno.

A leitura não se resume apenas na decodificação ou na oralização da escrita, como vem sendo realizada em algumas escolas, desconsiderando os aspectos sociais e as estratégias cognitivas. "A leitura não é uma questão de identificar letras, a fim de reconhecer as palavras para que se obtenha o significado das sentenças.” (SMITH, 2003, p. 201), toda via ler concerne ir além da decifração dos códigos e signos, para isso, é necessário que haja compreensão e interpretação daquilo que se lê, e entender o que o autor propõe em dizer em seu texto, como 
supõe Baldi (2009, p. 46), realizar a leitura, não apenas das palavras que estão explícitas, mas também daquelas que estão nas entrelinhas do texto. Ler é saber dialogar com o autor e ter capacidade de senso crítico quando necessário.

Contudo, alguns professores estão preocupados no ensino da gramática na escola utilizando o texto apenas como "pretexto para a construção de um outro objeto de ensino que não ele mesmo" (ROJO, 2006), ou resumindo a leitura apenas ao livro didático, sem motivação e sem perspectiva de aprendizado, apenas como reprodutor.

Nessa perspectiva SMITH (2003, p. 16), afirma:

[...] Existe, por exemplo, uma crença tradicional de que a leitura é simplesmente uma questão de "decodificação" de letras de palavras escritas em sons da fala, que este é, basicamente, um processo mecânico, e de que ensinar às crianças a ler deve envolver levá-las ao reconhecimento e mescla dos sons das letras $[\ldots]$.

Assim sendo, levando a leitura para sala de aula como um processo enfadonho e cansativo, apenas no sentido de reconhecer as letras. Essa prática tem transformado a leitura em uma atividade sem valor interacional, sem que se descubra o real sentido da leitura de um texto, considerando apenas o reconhecimento de palavras escritas.

Diante desse pressuposto, a prática da leitura na sala de aula vem sendo implantada como um processo de aquisição e de reconhecimento de códigos linguísticos, seguindo um planejamento desmotivador. Sendo esta uma abordagem de concepção da leitura ultrapassada que vê a sua aplicação nas escolas se tornando comum. Conforme Suassuna (2011, p. 108), esse tipo de ensino vem sendo abordado da seguinte forma: Os alunos realizam a leitura silenciosa de um determinado texto, em seguida o professor faz a leitura em voz alta, após, os alunos fazem a leitura também em voz alta. Desta atividade são formuladas perguntas relacionadas ao texto para que os alunos recordem os personagens principais, quais as partes mais "importantes" do texto, exercícios para retirada de frases prontas e etc. (BALDI, 2009, p. 46). Não obstante a leitura assume um viés de interesse avaliativo, em que são observadas as normas gramaticais de pontuação, memorização e compreensão do texto lido. Pressupondo que somente dessa forma seja possível realizar a abordagem do texto, considerando essa forma como único meio de interação texto-leitor. Como salienta Antunes (2003, p. 28):

Uma atividade de leitura puramente escolar, sem gosto, sem prazer, convertida em momento de treino, de avaliação ou em oportunidades para futuras "cobranças"; leitura que é, assim, reduzidos a momentos de exercícios, sejam aqueles da "leitura em voz alta" realizados, quase sempre com interesses avaliativos, sejam aqueles que têm de culminar com a elaboração das conhecidas "fichas de leitura". 
Não há um valor interacional pretendido pelo professor, ele não busca promover uma leitura em que o aluno seja sujeito da construção dos conhecimentos que serão adquiridos do texto e com o texto, como coloca Antunes (2003, p. 16-17), os enfoques dessas atividades puramente mecânicas estão relacionados apenas ao ensino da gramática, em uma concepção de leitura sem valor semântico, que faz com que o educando não consiga atribuir significados ao texto.

Antunes (2003) ressalta, alguns profissionais da educação têm voltado os objetivos das aulas de língua portuguesa para o ensino da gramática, uma metodologia de gramática descontextualizada, retrógrada e desvinculada com os conhecimentos de comunicações sociais dos alunos. Essas abordagens têm provocado nos alunos desinteresses pela leitura, visto que, a incompreensão após a realização da leitura de um texto ocasiona no aluno desmotivação, ceticismo em sua competência leitora levando-os ao desprezo na disciplina de português, como também resulta na formação de leitores com déficit na interação e compreensão textual, ou ainda evasão deste do processo de escolarização. Não há neste cenário uma proposta pedagógica que envolva e desperte nos alunos o interesse pela prática da leitura que contenha prazer, espontaneidade, que disponha relevância para sua abordagem, não apenas na sala de aula, mas também no seu meio social.

Antunes (2003, p. 66) afirma, “A leitura é a parte da interação verbal escrita, enquanto implica a participação cooperativa do leitor na interpretação e na construção dos sentidos e das intenções pretendidas pelo autor". Por conseguinte, é interessante que o professor considere o aluno como sujeito do ensino-aprendizado, mediando a interação dele com o texto, fazendo com que compreenda não somente o que está escrito no texto, mas qual a relevância que este tem para sua vida.

O aluno deve ser desafiado a buscar o envolvimento com a leitura, pois de acordo com Moura e Martins (2012, p. 89):

Percebemos a preeminente necessidade de a escola mudar o foco atual: deixar de considerar o ato de ler como atividade mecânica e de responsabilidade individual, para assumir a leitura como uma atividade em que os alunos e professores sejam sujeitos ativos e colaborativos.

Nesse sentindo, o aluno deve ser motivado a promover a interação entre autor-leitortexto (BORTONI-RICARDO et al., 2012), construindo intrinsecamente com o texto o significado para o que foi lido. Outro fator interessante, que não apenas deve ser considerado pelo professor, como também, reforçado por ele, são os conhecimentos e as experiências que o 
aluno adquirir do meio social, pois este é determinante na compreensão que o aluno terá na realização da leitura de qualquer texto.

De acordo com Freire (1989, p. 13), compreendemos o que lemos porque temos um conhecimento prévio da palavra, pois o mundo nos ensina sobre inúmeros fatores sociais, que nos são apresentados desde o nascimento, uma pessoa é capaz de ler e se comunicar através do conhecimento que foi adquirido por ela no meio social, esta aprendeu o significado de tudo que está relacionado no seu cotidiano, pois "a leitura do mundo sempre precede a leitura da palavra e a leitura desta implica a continuidade da leitura daquele". Precisamos ter um conhecimento prévio da leitura de mundo para dar sentido aos códigos e signos linguísticos, haja vista, que é a junção de ambos que implicará na compreensão de um texto.

Segundo Kleiman (2008, p. 25):

A ativação do conhecimento prévio é, então, essencial à compreensão, pois é o conhecimento que o leitor tem sobre o assunto que lhe permite fazer as inferências necessárias para relacionar diferentes partes discretas do texto num todo coerente. Este tipo de inferência, que se dá como decorrência do conhecimento de mundo e que é motivado pelos itens lexicais no texto é um processo inconsciente do leitor proficiente.

A prática da leitura deve ser explorada minuciosamente na sala de aula, fazendo com que o aluno identifique qual o sentido apresentado pelo texto e qual a relação do texto para com sua realidade do dia a dia, instigando-o à interação e construção de sentidos, pois para Antunes (2016, p. 67):

Nessa busca interpretativa, os elementos gráficos (as palavras, os sinais, as notações) funcionam como verdadeiras "instruções" do autor, que não podem ser desprezadas, para que o leitor descubra significações, elabore suas hipóteses, tire suas conclusões. [...].

Nesse seguimento, os textos necessitam de leitores capazes de dar sentido ao qeu foi lido, e cada leitor apresentará uma leitura particular, uma vez, que cada leitor possui conhecimentos e experiências únicas, pois o mundo não se configura da mesma forma para todos, sendo assim, deve-se mediar o aluno para que ele "mergulhe no universo literário" (BALDI, 2009, p. 47), adquirindo estratégias de leitura e aumentando sua fruição, todavia, não é somente a quantidade que determinará seu desenvolvimento na leitura, e sim o modo como serão explorados os textos, considerando as diversidades de gêneros textuais.

Nos anos iniciais do ensino fundamental os alunos têm pouco ou nenhum contato com outros gêneros textuais que não aqueles dos livros didáticos (MOURA; MARTINS, 2012), e é ai que entra o professor como mediador nesse processo de ensino, este deve proporcionar aos 
alunos condições necessárias para o aprendizado e aquisição da leitura. Propiciar ao aluno uma leitura sobre os textos contidos nos livros didáticos mediando a interação entre autor-textoleitor, explorando cada parte do texto, somando o que o texto apresenta com o conhecimento prévio que o aluno tem. O mediador deve ressignificar as práticas de leitura para que juntamente com o aluno dê sentido ao texto.

Como aponta Bortoni-Ricardo (2012, p. 88):

Nossa reflexão concentra-se na prática pedagógica, na perspectiva da mediação do ensino, revisitando alguns autores que nos oferecem aportes teóricos sobre a leitura a partir de um ponto de vista interacional, base de nossa atuação junto aos alunos colaboradores e da descrição das possibilidades de ressignificação dos momentos de leitura de textos de livros didáticos no espaço da sala de aula.

Diversos tipos de gêneros discursivos devem ser apresentados ao aluno, o professor, a partir deles, deve mediar o educando ao questionamento, a polemizar, criar hipóteses, construir críticas positivas e negativas. Assim permitir que o aluno seja sujeito e interaja com e sobre o texto.

Conforme Moura, Martins (2012, p. 107) é interessante que o educador por meio das práticas pedagógicas sobre as estratégias de leitura, desenvolva em seus alunos os aspectos cognitivos, assimilando o que aprendeu no texto com o conhecimento de mundo, sob uma percepção de intertextualidade, dessa forma, fazer o reconhecimento dos elementos linguísticos e também desenvolver no aluno a metacognição.

Como afirma Bortoni-Ricardo (2012, p. 68):

Mediar o desenvolvimento da leitura é exercitar a compreensão do aluno, transformando-o de leitor principiante em leitor ativo. Isso pressupõe desenvolver sua capacidade de ler com segurança, de decodificar com clareza e reconhecer com rapidez as palavras para uma leitura fluente. Realizar previsões, formular e responder questões a respeito do texto, extrair ideias centrais, identificar conteúdos novos e dados, relacionar o que ler com o que está subjacente ao texto, valer-se de pistas para fazer inferências, sumarizar, ser capaz de dialogar com outros textos são habilidades que vão construindo o sujeito leitor em formação em leitor proficiente. A mediação na leitura acontece na dinâmica da interação. O mediador apoia o leitor iniciante auxiliando-o a mobilizar conhecimentos anteriores para desenvolver as habilidades específicas para aquela tarefa.

Ainda que sejam encontradas dificuldades no ambiente educacional, a escola ainda é a principal formadora de leitores, por tanto, o professor como mediador desse conhecimento deve-se fazer ativo, conhecer e praticar a leitura de forma prazerosa, tendo uma concepção de leitura que vise possibilitar ao educando habilidades para realizar uma leitura significativa, para 
que o sujeito/aluno adquira funções imprescindíveis como percepção, habilidades cognitivas, competência leitora, interação, memorização, autonomia entre outros benefícios que a prática da leitura proporciona.

Partindo desse pressuposto, o professor ao desenvolver uma proposta pedagógica pautada em uma concepção de leitura que leve em conta os fatores linguísticos e discursivos em sua mediação, contribuirá significativamente para que o educando se aproprie da leitura no processo de ensino-aprendizado, nesse sentido mediando o aluno a tornar-se leitor proficiente.

\section{O que dizem os documentos oficiais de ensino sobre a leitura e formação do leitor}

Para que sejam realizadas práticas pedagógicas condizentes para formação do educando com proficiência, considerando educação de qualidade para todos, por conseguinte, fazer a inserção da criança no mundo letrado, assegurando o ensino da leitura e a formação do leitor, faz-se necessário conhecer os documentos oficiais sobre o ensino da leitura nos anos iniciais do ensino fundamental. Foram criados instrumentos legais para garantir ensino de qualidade visando o pleno desenvolvimento do indivíduo. Para a aplicabilidade desse ensino, na educação básica, descreve o Art. 211 da Constituição Federal (1988): “a união, os Estados, o Distrito Federal, e os Municípios organizarão em regime de colaboração seus sistemas de ensino", assim, criando currículos pedagógicos que possibilitem as estratégias necessárias para sua atuação no meio social. Conforme a secção III da LDB, Lei 93.94/96, que trata sobre o Ensino Fundamental, “Art.32. I- O desenvolvimento da capacidade de aprender, tendo como meios básicos o pleno domínio da leitura, da escrita e do cálculo".

Nesse sentido, criando propostas de currículos e diretrizes educacionais que proporcionem ao indivíduo meios para que este se aproprie de conhecimentos essenciais para seu desenvolvimento pleno.

Assim, pontua o Art.26 da LDB:

Os currículos do ensino fundamental e médio devem ter uma base nacional comum, a ser complementada, em cada sistema de ensino e estabelecimento escolar, por uma parte diversificada, exigidas pelas características regionais e locais da sociedade, da cultura, da economia e da clientela.

Sendo assim, em 2014, foi criado o Plano Nacional de Educação (PNE), que é um documento que contêm vinte metas com a finalidade de direcionar medidas a serem adotadas para elevar o ensino a uma educação de qualidade e igual para todos em dez anos. Nesse plano encontra-se, na meta 5 do PNE, a incumbência de alfabetizar as crianças até o $3^{\circ}$ ano do Ensino 
Fundamental, na perspectiva de que estas se apropriem da leitura, escrita e habilidades matemáticas como forma de auxiliarem, não apenas, no desenvolvimento das capacidades cognitivas do indivíduo, como também, uma atuação valorosa diante de diferentes gêneros e práticas discursivas. O PNE (2014) enfatiza que:

A alfabetização hoje não pode ser considerada uma (de)codificação mecânica de letras e sílabas; ela deve ser entendida em relação a efetiva participação das crianças nas práticas de letramento às quais se encontram expostas, dentro e fora da escola. Assim, torna-se necessário tomar os usos e as funções da língua escrita com base na elaboração de atividades significativas de leitura e escrita nos contextos em que vivem as crianças.

Sendo assim, a prática pedagógica que deverá nortear o ensino na alfabetização, disporá de estratégias que envolvam a participação ativa no processo de formação do sujeito, considerando um ensino com aspectos significativo sobre a leitura e a escrita. Nesse contexto, o Pacto Nacional pela Alfabetização na Idade Certa (PNAIC), assumiu um compromisso com a educação federativa de assegurar que até o $3^{\circ}$ ano do ensino fundamental, que todas as crianças na faixa etária de oito anos estejam alfabetizadas. O PNAIC compreende que até essa idade as crianças devem compreender normas simples da gramática, tais como “[...] o domínio das correspondências grafônicas, mesmo que dominem poucas convenções ortográficas irregulares e poucas regularidades que exijam conhecimentos morfológicos mais complexos", também fluência na leitura, na compreensão e produção textual, saiba distinguir gêneros discursivos, noção temporal e reconhecer a finalidade do texto (BRASIL, 2014, p. 86). Conforme MEC (2014):

O PNAIC apresenta, assim, quatro princípios que devem ser considerados, quais sejam: o sistema da escrita alfabética é complexo e exige um ensino sistemático e problematizador; o desenvolvimento das capacidades de leitura e de produção de textos ocorre durante todo o processo de escolarização, mas deve ser iniciado logo no início da educação básica, garantindo acesso precoce a gêneros discursivos de circulação social e a situações de interação em que as crianças se reconheçam como protagonistas de suas próprias histórias; conhecimentos oriundos das diferentes áreas podem e devem ser apropriados pelas crianças, de modo que elas possam ouvir, falar, ler, escrever sobre temas diversos e agir na sociedade; a ludicidade e o cuidado com as crianças são condições básicas nos processos de ensino aprendizagem (BRASIL, 2014, p. $88)$.

Desse modo, o plano visa o desenvolvimento das habilidades cognitivas do educando, bem como, a aquisição das habilidades de leitura e escrita, analisando através dos resultados da Avaliação Nacional da Alfabetização (ANA), melhorias no ensino, para que a partir desta, 
sejam providenciadas ações com estratégias pedagógicas pertinentes à formação do educando, cujo, ensino seja de qualidade.

Na meta 7 do PNE, também visando o desenvolvimento dos alunos no processo de ensino aprendizagem, está a proposta de implantar na educação básica diretrizes pedagógicas voltadas para um ensino de qualidade, esta meta propõem implantação de estratégias necessárias para melhorias no aprendizado do educando, tais como, a Base Nacional Comum dos Currículos, visando alcançar o desenvolvimento total na educação básica.

Isto posto, entra em cenário a Base Nacional Comum Curricular (BNCC), que é um documento normativo que norteia os currículos educacionais da federação, este documento abrange os níveis da educação básica da pré-escola ao ensino médio, e visa as aprendizagens essenciais para o desenvolvimento pessoal do indivíduo e a formação plena nos seus aspectos individuais e coletivos, ou seja, de sua totalidade. "Trata-se, portanto, da implantação de uma política educacional articulada e integrada" (BRASIL, 2017, p. 05). Nessa perspectiva a BNCC busca com sua política educacional de implantação, desenvolver no educando competências e habilidades necessárias para uma vida ativa em sociedade, pois segundo a BNCC (BRASIL, 2017, p. 14):

No novo cenário mundial, reconhecer-se em seu contexto histórico e cultural, comunicar-se, ser criativo, analítico-crítico, participativo, aberto ao novo, colaborativo, resiliente, produtivo e responsável requer muito mais do que o acúmulo de informações. Requer o desenvolvimento de competências para aprender a aprender, saber lidar com a informação cada vez mais disponível, atuar com discernimento e responsabilidade nos contextos das culturas digitais, aplicar conhecimentos para resolver problemas, ter autonomia para tomar decisões, ser proativo para identificar os dados de uma situação e buscar soluções, conviver e aprender com as diferenças e as diversidades.

Uma proposta de ensino que vise a autonomia do educando, no sentido de ter competências necessárias para atuar como sujeito participativo e colaborativo na sociedade. Nesse sentido, a BNCC compromete-se com um modelo de educação integral, para que assim se possa desenvolver no educando autonomia para que este se torne proativo no meio social, considerando as especificidades e diversidades dos alunos no ambiente escolar.

No que se refere à leitura nas series iniciais do Ensino Fundamental, neste documento normativo, sua abordagem na área da linguagem, com ênfase na disciplina de língua portuguesa, tem como objetivo a comunicação e expressão do indivíduo, possibilitando sua inserção no mundo letrado para que este se aproprie de conhecimentos através de experiências e interação com novos saberes, pois como coloca este documento. 
A BNCC do ensino fundamental - Anos Iniciais, ao valorizar as situações lúdicas de aprendizagens, aponta para a necessária articulação com as experiências vivenciadas na Educação Infantil. Tal articulação precisa prever tanto a progressiva sistematização dessas experiências quanto o desenvolvimento, pelos alunos, de novas formas de relação com o mundo, novas possibilidades de ler e formular hipóteses sobre os fenômenos, de testálas, de refutá-las, de elaborar conclusões, em uma atitude ativa na construção de conhecimentos (BRASIL, 2017, p. 56).

Nesse sentido, os alunos nesse nível educacional devem ser inseridos no mudo letrado como sujeitos no processo de ensino-aprendizagem, uma vez que, nessa fase de ensino os alunos estão em processo de aquisição e construção de conhecimentos, novas descobertas, variedades de novas informações que despertam curiosidades sobre o "novo", nesse sentido a leitura deve ser apresentada como prática social de valor interacional.

Na BNCC, abordagens pedagógicas de leitura estão intrinsecamente atreladas à língua portuguesa, esta tem como base para sua aplicabilidade de ensino os textos, pois como situa Kleiman (2008, p. 45), “O texto é considerado por alguns especialistas como uma unidade semântica onde os vários elementos de significação são materializados através de categorias lexicais, sintáticas, semânticas, estruturais". Nesse sentido

Tal proposta assume a centralidade do texto como unidade de trabalho e as perspectivas enunciativo-discursivas na abordagem, de forma a sempre relacionar os textos e seus contextos de produção e o desenvolvimento de habilidade ao uso significativo da linguagem em atividades de leitura, escrita e produção de textos com várias mídias e semioses (BRASIL, 2017, p. 65).

Nessa perspectiva, esse tipo de abordagem leva em consideração, nas suas práticas de ensino da linguagem, todos os tipos de gêneros discursivos que devem ser realizados em prol do desenvolvimento da capacidade leitora, para que dessa forma seja possível ao aluno apropriar-se de diferentes gêneros e saber interpretá-los, fazendo as inferências corretas, sendo capaz de compreender as características do elemento textual.

O eixo de leitura compreende as práticas de linguagem que decorrem da interação ativa do leitor/ouvinte/espectador com os textos escritos, orais e multissemióticos e de sua interpretação, sendo exemplos a leitura para: fruição estética de textos e obras literárias; pesquisa e embasamento de trabalhos escolares e acadêmicos; realização de procedimentos; conhecimento, discussão e debate sobre temas sociais e relevantes; sustentar a reivindicação de algo no contexto de atuação da vida pública; ter mais conhecimento que permita o desenvolvimento de projetos pessoais, dentre outras possibilidades (BRASIL, 2017, p. 69).

O ambiente escolar deve ter uma proposta de ensino que consiga contribuir para que o indivíduo adquira autonomia para realizar atividades sociais significativas dentre os mais 
diversos gêneros discursivos, de forma que acompanhe a contemporaneidade e o desenvolvimento das tecnologias digitais da informação e comunicação (TIDIC) (BRASIL, 2017, p. 65), que traz para a sociedade textos multimodais e multissemióticos. Estes são, segundo a BNCC, ferramentas importantes para o desenvolvimento e interação do aluno na aquisição e compreensão do mundo letrado, uma vez que

Leitura no contexto da BNCC é tomada em um sentido mais amplo, dizendo respeito não somente ao texto escrito, mas também a imagens estáticas (foto, pintura, desenho, esquema, gráfico, diagrama) ou em movimentos (filmes, vídeos e etc.) e ao som (musica), que acompanha e cossignifica em muitos gêneros digitais (BRASIL, 2017, p. 70).

Sendo assim, as práticas de leitura relacionam-se com os acontecimentos do meio social, as diferentes mídias que circulam no mundo, reflexões sobre textos sócio-histórico, multimidiáticos, multissemióticos e os hipertextos. Segundo Kleiman (2014), esses tipos de gêneros discursivos “[...] nos propiciam leituras cada vez mais livres, em que diferentes modos de comunicação contribuem com diferentes significados [...]”. Para que, dessa forma, seja possível engendrar o sujeito, que ao realizar a leitura de um texto, saiba fazer as inferências necessárias para identificar de qual gênero o texto trata; qual o papel do autor no texto; quais as perspectivas e hipóteses adotadas sobre o texto; o que o texto apresenta semelhante a sua realidade; realizar uma leitura crítica do texto; tenha discernimento nos fatos ocorridos no texto, e não menos importante, dar sentido ao texto. Ressalta-se:

Como já ressaltado, na perspectiva da $\mathrm{BNCC}$, as habilidades não são desenvolvidas de forma genérica e descontextualizada, mas por meio da leitura de textos pertencentes a gêneros que circulam nos diversos campos de atividade humana. Daí que, em cada campo que será apresentado adiante, serão destacadas as habilidades de leitura, oralidade e escrita, de forma contextualizada pelas práticas, gêneros e diferentes objetos do conhecimento em questão.

A demanda cognitiva das atividades de leitura deve aumentar progressivamente desde os anos iniciais do Ensino Fundamental até o Ensino Médio. Esta complexidade se expressa pela articulação:

- da diversidade dos gêneros textuais escolhidos e das práticas consideradas em cada campo;

- da complexidade textual que se concretiza pela temática, estruturação sintática, vocabulário, recursos estilísticos utilizados, orquestração de vozes e linguagens presentes no texto;

- do uso de habilidades de leitura que exigem processos mentais necessários e progressivamente mais demandantes, passando de processos de recuperação de informação (identificação, reconhecimento, organização) a processos de compreensão (comparação, distinção, estabelecimento de relações e inferência) e de reflexão sobre o texto (justificação, análise, articulação, apreciação e valorações estéticas, éticas, políticas e ideológicas);

- da consideração da cultura digital e das TDIC; 
- da consideração da diversidade cultural, de maneira a abranger produções e formas de expressão diversas, a literatura infantil e juvenil, o cânone, o culto, o popular, a cultura de massa, a cultura das mídias, as culturas juvenis etc., de forma a garantir ampliação de repertório, além de interação e trato com o diferente (BRASIL, 2017).

Essa proposta se dá para envolver os estudantes em atividades de leitura que possibilitem o desenvolvimento cognitivo, interações com experiências que promovam ampliar seu repertorio vocabular, a partir de conhecimentos extraídos e das significações que este faz do objeto de leitura se utilizando de seus conhecimentos prévios. Dessa maneira, esse tipo de abordagem desenvolve habilidades e competências para a realização de uma leitura significativa sob a perspectiva de diferentes gêneros discursivos. Essa é a proposta de ensino que a BNCC propõe, realizar sua aplicabilidade nas series iniciais do ensino fundamental e nas series seguintes do ensino básico, na perspectiva de formar leitores capazes de compreender os textos e seus contextos.

Somado a isso, na perspectiva de reforçar a política da leitura nos currículos pedagógicos de ensino nas escolas, foi instituída a Política Nacional da Leitura e Escrita, Lei 13.696 de 12 de julho de 2018, como forma de garantir a abordagem da leitura e escrita no ensino, bem como: acesso a livros, espaços de leitura/escrita, bibliotecas, feiras literárias e etc., desde que sejam de acesso público. Esta política fortalece a importância da leitura no ambiente educacional e na formação do educando no processo de ensino-aprendizagem, salienta também, a atuação do mediador frente às ações de ensino no processo de mediação da leitura, conforme menciona no Art.3- II desta Política:

Fomentar a formação de mediadores de leitura e fortalecer ações de estímulo à leitura, por meio da formação continuada em práticas de leitura para professores, bibliotecários e agentes de leitura, entre outros agentes educativos, culturais e sociais; (BRASIL, 2018).

Dessa maneira, contribuir com as políticas educacionais de leitura, para fortalecer a importância e o incentivo da leitura no âmbito escolar e fora dele, assim dispor de atividades que permitam educador e educando a terem totais acesso a mecanismos de leitura. Contudo, o mediador deve estar ciente sobre a relevância que a leitura apresenta na vida do indivíduo, portanto, este deve oferecer estratégias na abordagem da leitura que ensejem o educando, instrumentos necessários para estimular a capacidade leitora do aluno, visto que, no Art. 3-X, diz:

Incentivar a expansão das capacidades de criação cultural e da compreensão leitora, por meio do fortalecimento de ações educativas e culturais focadas no 
desenvolvimento das competências de produção e interpretação de textos (BRASIL, 2018).

Portanto, assim como os documentos anteriores citados, este também visa o desenvolvimento das competências e habilidades cognitivas e linguísticas do indivíduo no processo de formação do sujeito leitor crítico-reflexivo. Atualmente, as políticas, diretrizes e estratégias criadas foram pensando em um ensino-aprendizado que proporcione ao educando a compreensão significativa do que é o ato de ler, e quais os benefícios que este proporciona, não apenas, no processo de escolarização, mas também, na vida em sociedade.

\section{Considerações finais}

Muitos serão os percalços do educando no processo de escolarização, ou seja, ao longo da educação básica. Desenvolver nesses educandos as competências e habilidades de leitura é algo necessário para que estes exerçam seu papel de cidadão crítico e reflexivo na sociedade, e que dessa forma possam ser protagonistas de suas histórias.

Para que ocorra o avanço da prática de leitura em sala de aula, e assim amenizar o número de pessoas que tem dificuldades na aquisição desta, é necessário que os professores sejam mais comprometidos com a desmistificação das relações sociais, que busquem ter clareza teórica sobre sua concepção de leitura, para que dessa forma estimulem as discussões, as pesquisas, as hipóteses, o debate e o enfrentamento de tudo que constrói o ser. Assim, sendo mais flexível em sua prática pedagógica, se torna mais sensível à apreensão de possibilidades alternativas, ao seu fazer em sala de aula, indo além das atividades imediatistas e sempre buscando desenvolver e construir no/com educando o comportamento leitor.

Para que essas ações se concretizem, contamos com Lei, Diretrizes e Políticas educacionais que asseguram que os aspectos de leitura sejam desenvolvidos no educando em seu processo de escolarização, criando planos e metas para que a leitura seja estimulada e concebida de forma consciente por eles. Documentos estes que amparam o direito a uma educação de qualidade, que vise desenvolver habilidades e competências necessárias para práticas sociais do indivíduo, com a pretensão de aclarar que a leitura é necessária e significativa na vida do ser humano. Não apenas como uma prática social, mas também como um dos prazeres da vida. 


\section{REFERÊNCIAS}

ANGELO, C. M. P. Conceitos de leitura. In: MENEGASSI, R. J. (Org.). Leitura e ensino: Formação de Professores EAD, 19. Maringá: EDUEM, 2005.

ANTUNES, I. Aula de português: encontro e interação. São Paulo: Parábola, 2003.

BALDI, E. Leitura nas series iniciais: uma proposta para formação de leitores de literatura. Porto Alegre: Projeto, 2009.

BORTONI-RICARDO, S. et al. Leitura e mediação pedagógica. São Paulo: Parábola, 2012.

\section{BRASIL. Constituição da República Federativa do Brasil de 1988.}

BRASIL. Lei n. 9.394 de 20 de dezembro de 1996. Estabelece as diretrizes e bases da educação nacional. Diário Oficial da União, Brasília, DF, 23 dez. 1996.

BRASIL. Lei n. 13.005, de 25 de junho de 2014. Aprova o Plano Nacional de Educação (PNE) e dá outras providências. Diário Oficial da União, Brasília, DF, 26 jun. 2014. Disponível em: https://www2.camara.leg.br/legin/fed/lei/2014/lei-13005-25-junho-2014-778970publicacaooriginal-144468-pl.html. Acesso em: 26 set. 2019.

BRASIL. Base Nacional Comum Curricular. Brasília (BNCC): MEC. 2017. Disponível em: http://basenacionalcomum.mec.gov.br/imagens/BNCC_20dez_site.pdf. Acesso em: 26 set. 2019.

BRASIL. Lei n. 13.696 de 12 de julho de 2018. Institui a Política Nacional de Leitura e Escrita. Diário Oficial da União, Brasília, DF, 13 jul. 2018. Disponível em: http://www.planalto.gov.br/ccivil_03/_ato2015-2018/2018/Lei/L13696.htm. Acesso em: 26 set. 2019.

COELHO, K.; MACHADO, M. A importância da leitura na educação infantil: um estudo teórico. Disponível em: https://fapb.edu.br/wpcontent/uploads/sites/13/2018/02/especial/4.pdf. Acesso em: 15 abr. 2019.

FREIRE, P. A importância do ato de ler em três artigos que se completam. 23. ed. São Paulo: Cortez, 1989.

HOPPE, M.; COSTA-HÜBES, T. Concepções de leitura na educação básica e a sua relação com a prova brasil. $\mathrm{s} / \mathrm{d}$.

KLEIMAN, A. Abordagens da leitura. Belo Horizonte, Scripta, 2004.

KLEIMAN, A. Texto e leitor: aspectos cognitivos da leitura. 11. ed. São Paulo: Pontes, 2008.

KLEIMAN, A. Letramento na contemporaneidade/ Literacy in the Contemporary Scene. Bakhtiniana, São Paulo, v. 9, n. 2, p. 72-91, ago./dez. 2014. Disponível em: https://revistas.pucsp.br/bakhtiniana/article/view/19986/15597. Acesso em: 26 set. 2019. 
ROJO, R. Alfabetização e letramento: sedimentação de práticas e (des)articulação de objetos de ensino. Perspectiva, Florianópolis, v. 24, n. 2, p. 569-596, jul./dez. 2006. Disponível em: https://periodicos.ufsc.br/index.php/perspectiva/article/view/1663. Acesso em: 26 set. 2019.

SMITH, F. Compreendendo a leitura: uma análise psicolingüística da leitura e do aprender a ler. 4. ed. Porto Alegre: Artmed, 2003.

SUASSUNA, L. Ensaios de pedagogia da língua portuguesa. 3. ed. Recife: Ed. Universitária da UFPE, 2011.

\section{Como referenciar este artigo}

BANDEIRA, M. Á.; PORTILHO, R. Concepções de leitura e formação do leitor nos anos iniciais do ensino fundamental nos documentos oficiais de ensino. Doxa: Rev. Bras. Psico. e Educ., Araraquara, v. 22, n. 1, p. 171-188, jan./jun., 2020. e-ISSN: 2594-8385. DOI: https://doi.org/10.30715/doxa.v22i1.13977

Submetido em: 20/12/2019

Revisões requeridas em: 30/04/2020

Aceito em: 28/05/2020

Publicado em: 01/06/2020 